\title{
产业扶贫存在的问题与建议
}

\author{
谭玲惠 \\ 中共石柱土家族自治县委党校 \\ DOI:10.32629/ej.v2i6.321
}

[ 摘 要] 长期以来,产业扶贫对于推动贫困群体脱贫致富、带动贫困地区整体发展方面有着重要作用。推动贫困地区的产业发展是产业扶 贫的重要举措,贫困地区产业发展与开发的程度、深度与涉及产业发展的各类生产要素的组织水平和组织模式密不可分。党的十八大以来, 我县产业扶贫在组织形式方面进行和大胆的创新和实践,推动着产业扶贫的深入发展。然而,笔者通过对全县产业发展调研发现我县通过大 力培育发展长效产业至今, 部分产业发展存在效益不佳, 产业扶贫效果不明显等问题, 如何培优做强优势产业, 助力精准扶贫,笔者提出了几点 粗浅的建议。

[关键词] 产业扶贫; 问题；建议

\section{1 扎实推进产业发展,助推脱贫攻坚的重要性}

从“五个一批” 中 “发展生产脱贫一批” 的优先摆位, 到乡村振兴的 “五个振兴” 中 “产业振兴” 的首要地位, 都表明了习近平总书记对产业 发展的高度重视, 也反映了产业扶贫在脱贫攻坚中无可替代的重要作用。 2016年4月, 习近平总书记在安徽考察时指出: “要脱贫也要致富, 产业扶贫 至关重要, 产业要适应发展需要, 因地制宜、创新完善。”同年7月, 习近平 总书记在宁夏考察时强调, 发展产业是实现脱贫的根本之策, 把培育产业 作为推动脱贫攻坚的根本出路。这些重要论述, 把准了打赢脱贫攻坚战的 根本, 指明了决胜全面小康的方向。发展产业既是带动群众就业、促进群 众增收最直接最有效的路径, 更是实现 “两不愁三保障” 目标最有力最 可靠的支撑。我们要把习近平总书记扶贫重要论述作为打赢打好脱贫攻 坚战的制胜法宝, 将贯穿其中的科学思维方法运用到工作实践之中, 统 筹脱贫攻坚各项工作, 抓好产业扶贫这个实现脱贫的根本之策, 统筹推 进产业振兴。

\section{2 目前我县产业发展取得的成绩及存在的问题}

2. 1 产业发展缺乏规划, 项目论证不充分。在XX镇金银花项目上, 全县 在2012年发展了15个乡镇, 目前无一个乡镇还有该项目的存在, 就XX金银 花项目看, 当时群众讨论一句话, 没有科学论证。后来, 因金银花受市场影 响太大, 开始规划时期望值太高, 从亩产值 9600 元的期望值变为不足 1000 元。同时, 金银花管理成本和采摘劳动强度上都让当地群众感受到不如种 传统的农作物。因此, 栽种第三年, 原本品种和成活率都高的项目, 老百姓 直接毁掉, 导致国家审计该扶贫资金时指出 “成活率低, 效益不好”。同 样, XX花椒项目在接受审计时被指出 “成活率低, 项目论证不充分”, 辣椒 对土壤、水分、空气、温度适应性较差, 气温急剧变化、空气中有害气体 积累、湿度过大、药害、土壤干旱、水涝、枝叶郁闭、透光不良等因素都 能使叶片变黄或浅褐色, 叶柄生成离层而落叶, 特别是花椒树的耐用寒能 力较弱。然而, 在XX乡海拔高度接近 1000 米的地方种植一定是论证不充分, 导致后期成活率不高, 产业发展失败。本来农业产业就是属于“三高一低”, 科技含量要求高、受外界自然气候影响高, 产出及市场风险高、回报率低。 因此, 项目在规划时一定要准确, 论证必须充分。

2. 2 产业基地基础设施不完善, 投入成本大。产业基地基础设施建设滞 后, 排灌沟渠和蓄水设施不配套, 进出基地的机耕道路缺乏, 生产作业便道 不畅, 严重影响农产品的生产和运输。导致耕作成本过高。我县多数地块 属于“鸡窝地”, 多数地块无法实现机械化作业, 并且高中低海拔分布明显, 导致产业的碎片化比较严重, 修建产业便道的成本高。比如, XX油茶项目, 总布局1100亩左右, 在田间管理, 除草、上肥、培土全靠人工作业, 田间管
理的滴灌上肥设施、产业便道修建成本高, 基础设施投入高, 修建不完善。 后期管护成本高, 导致本身见效都很慢的油茶项目, 后期管护脱节。

2. 3优质产业单品量小, 产业链条延伸不够。前年以来, 我县强力推进 产业结构调整后, 全县的产业优势有所彰显。但是, 农产品储藏、加工、运 销能力滞后, 初级产品、粗加工、低附加值产品多, 精深加工、高附加值产 品少; 其次, 农业龙头企业少且实力较弱, 全县仅有县级以上农业龙头企业 83家, 深加工企业产品研发和投产能力不足, 带动贫困户增收困难。当然主 要原因是, 我们优质的农产品的产量不多, 如XX镇油茶项目, 本来油茶项目 是特色优质项目, 习近平总书记在今年前往调研河南省光山县时还专门视 察司马光油茶园, 可见油茶项目的发展优势。但是, 就XX镇1000亩油茶项目 来说, 不多又不少, 建厂成本高, 不建厂产业附加值又不高。类似这样的项 目, 在全县没有形成一盘棋, 乡镇 (街道) 各自为政, 缺乏统筹意识。

2.4 农村劳动力短缺、原产地组织生产环节呈现危机。农业兼业化、 农村空心化、农民老龄化现象突出, 农业现代化与青壮年劳动力紧缺, 专业 型、复合型的农业人才更是 “一将难求”。“谁来种地、如何种地”已成为 函待破解的一大难题。随着大量青壮劳动力外出, 留守在家的妇女、老人 不得不种 “省事田”、“懒人田”, 粗放经营, 甚至抛荒耕地。去年, 我对于 XX乡的辣椒产业做了调研, 从种植面积看, 全乡实际辣椒面积从 2014年 4550 亩, 2015年3200亩, 2016年2430亩, 2017年的1930亩, 2018年1720亩, 从 种植人员看, 2018 年种植人员 672 户, 其中, 40 岁以下种植的有 2 户, 40 岁到 49岁的有129户, 50 岁到 59 岁177户, 60 岁到69岁的有235户, 70到79岁的有 126 户, 甚至还有 3 个户是 80 岁以上 3 个户的种植了 6 亩。由此可见, 尽管辣椒 收购价格一年不一年高, 但是作为要用 11 道工序种出来的辣椒产业, 将面 临着越来越少的人再种下去。

\section{3 关于我县大力培育优势产业的几点建议}

3. 1 产业布局须落实规划先行, 论证要充分。在项目发展过程中, 不仅 要争取群众意见, 政府部门必须充分论证, 要找专业的行业部门做好可行 性论证, 实施方案制定科学, 操作性强。同时, 全县要形成一盘棋, 县上在做 产业时, 要多省市对比调研, 行业主管部门发挥好参谋长, 指挥棒作用。

3. 2 注重招优引强, 积极培育引进龙头企业。一是积极培育壮大本土农 业企业。围绕木本中药材、有机茶叶、柠檬产业鼓励县内农业龙头企业扩 展和做大现有基地规模。二是加大招商引资力度。重点围绕有机茶叶、皱 皮木瓜等实行一企一策, 有针对性的 “点对点” “面对面” 精准招商。三是 资源各方整合, 落实好土地、资本、技术、信息等生产要素, 实现齐抓共管 产业大格局。

3. 3加大扶贫带动, 完善利益联结机制。以农业产业结构深度调整为支 


\title{
论小微企业的治理
}

\author{
龚进富 \\ 启晗电力建设集团有限公司 \\ DOI:10.32629/ej.v2i6.334
}

[摘 要] 中国的企业平均寿命不到 6.8 年，小微企业寿命平均只有 3.7 年; 小微企业从业人员众多、是社会最基层的经济组织、为社会经济的发 展和社会稳定做出了很大贡献。是什么原因造成小微企业的短命呢? 在企业的发展过程中、影响企业发展的因素有很多; 环境、战略、人才、 资金、制度、技术等等。但调查发现，很多的小微企业并不是因为生存的原因而倒闭的，更多的原因是因为合伙人之间出现了矛盾、企业组 织出现了问题而倒闭。追根溯源，如何完善合伙制、如何打造自我更新、自我强化的股东组织，是小微企业基业长青的根本。

[关键词]企业的社会发展; 生命周期; 发展要素; 治理格局

\section{1 人类社会的发展和中国人的历史文化}

文明是人类智慧的结晶, 人类社会的发展、从农耕文明到工业文明, 从手工作坊到流水线, 不断改变着世界的面貌和人们的生活。企业是社会 的基本经济组织, 他按一定方式组织生产要素进行生产、经营活动, 是社 会经济活动的基础。

伴随着社会的发展, 社会文明程度越高、社会化分工越细。当今社会 正处于一个大变革时期, 一个人的力量是微弱的, 要想做点事, 要么加入 一个组织、要么创建一个组织, 用组织的力量去实现我们的愿景。

中国人、两千年来文化的积淀、很多已经成为我们生命的基因。“生 意好做, 伙计难搁” 的浐语充分说明了合伙做事的难度; 兄弟式合伙仇人 式散伙成为很多企业的真实写照。中国人宁做鸡头不做凤尾的思想, 也极 容易分裂组织、另起炉灶、另立山头; 但山头太小就容易被消灭。这也是 小微企业生命力不长久的最主要原因。

\section{2 组织的生命周期}

根据组织周期理论: 每个组织都经历一定的生命周期, 一般来讲有四 个阶段：初创期、成长期、成熟期、衰老期。

初创期: 是指组织的创立初期, 这段时期明显的特征是: 兴奋、对未 来充满憧憬、对组织成员的缺点呈显极大的包容性、对组织成员的优点扩 大 有人也把这个时期称为方奋期、还有人把这段时期比喻为组织的春季 或蜜月期。

成长期: 是指组织经过蜜月期后的一段时期: 这段时期的特征是: 对 组织成员的缺点扩大, 对优点熟视无睹、包容性下降; 组织中充满抱怨、 恼怒、消极的工作氛围; 对未来的前景没有信心，组织成员之间的信任感 下降。有人把这段时期也称为混乱期; 也有人把这段时期比喻为组织的夏 季或危险期。在这个季节、有狂风有暴雨、甚至还有冰雨, 很多小微企业 组织都是在这个阶段倒闭的。

成熟期: 就像婚姻一样, 渡过了三年之痛七年之痒, 婚姻的牢固性就
撑, 围绕资源变资产、资金变股金、农民变股东的 “三变” 改革, 以 “股份 农民” 为核心, 大力推进经营主体与贫困群众多形式开展 “合股联营”, 因地制宜推进土地经营权入股、土地流转、订单生产等多种经营方式。在 选择合作经营主体时, 基层村支两委、乡镇 (街道)干部、驻村工作队以及 贫困群众积极主动参与甄别, 在充分考量经营主体诚信度以及生产状况的 基础上, 优中选优, 确保 “企业+农户” 双获利。

3. 4 树立品牌, 持之以恒争特色示范县。坚持不解主要围绕全县 “ $3+3$ ” 特色农业产业, 特别加大产业结构深度调整中的干鲜果、中药材、休闲乡 村旅游等长效增收产业和调味品、有机蔬菜、生态养殖等特色产业。杜绝
会明显增强。在这个时期: 大家的心绪都会慢慢沉静下来, 对组织成员的 优点和缺点也会有一个客观的认识和评价, 包容性增强。组织愿景更加客 观真实, 组织成员之间信任感增强。也有人把这段时期比喻为组织的秋季, 秋天如人到中年: 少了一份轻狂、多了一份沉静; 没有了鲜花而拥抱了果 实; 秋天让我们拥有了一份 “宠辱不惊, 看庭前花开花落; 去留无意, 望 天上云卷云舒” 的淡定。

衰老期: 就象没有长生不老的人一样, 也没有永生的组织。当组织发 展的一定阶段以后, 也会象人样老去。我们不要试图去改变这种规律, 更 重要的是去尊重和享受这种规律带来的美好经历! 冬天来啦, 春天还会远 吗? 当一个生命老去的时候, 另外一个生命就要涎生了! 所以我更喜欢把 这个时期称作转型期。

3 现代企业发展三要素: 领导人、战略、执行

在市场经济的环境下, 企业首先要解决生存的问题。中国伟大的企业 家之一史玉柱先生曾说过: 不盈利的企业是不道德的。阿里巴巴的创始人 马云先生也说过: 企业的第一战略是生存! 今天很难、明天更难、后天很 美好; 可惜明天晚上你倒闭了, 就不能看到后天的太阳!

改革开改三十年、中国企业从计划经济到市场经济, 经过了一个翻天 覆地的历程。很多企业在兴起消亡, 有一点正被越来越多的企业家所认同: 现代企业发展三要素: 领导人、战略、执行。

领导人: 是起带头作用, 指导被领导者朝既定的目标前进的人, 是 为实现组织的目标而运用权力向其下属施加影响力的一种行为或过程。 在任何组织中都必须有一个最高领导人, 雁、无头不飞。领导人是带头 大哥、是旗帜、是灯塔、是领路人。领导人的战略眼光、管理思维、人 格魅力、心胸格局、整合资源的能力, 是组织能否取得最终成功的决定 性因素之一。

战略: 战略是通过定位, 以建立持久的竞争优势为目的的一系列基于 配称的协调的行动。原来的企业管理理论认为: 细节决定成败; 现在的企

“猴子搬包谷”, 全县要将农业产业提升到 10 年规划甚至 20 年规划, 一届政 府接着一届干。

[参考文献]

[1]邰燕.产业扶贫着力 “四变” 破解 “四难” [J]. 重庆行政(公共论 坛),2016,17(04):40-41.

[2]莫静玲, 韦兰英,赵倩欣,等.产业扶贫存在的问题及对策[J].湖北农 业科学,2019,58(S1):165-166.

[3]乔栋明. 加快产业培育步伐坚决打赢脱贫攻坚战 [N]. 民族日 报,2018-07-29(001). 